\title{
EDUCAÇÃO TRADICIONAL E EDUCAÇÃO MODERNA NA REGIÃO CENTRO- SUL DA BAHIA NO CONTEXTO DO PROJETO COLÚMBIA
}

Edileusa Santos Oliveira leu_vc@yahoo.com.br

Ana Palmira Bittencourt Santos Casimiro apcasimiro@oi.com.br

Ruddy Aquino Wanderlei ruddyaquino@gmail

Universidade Estadual do Sudoeste da Bahia - UESB

\section{RESUMO}

A pesquisa em andamento, considerando a implantação do Programa de Pesquisas Sociais do Estado da Bahia e a atuação do educador Anísio Teixeira à frente da Secretaria de Educação e Saúde da Bahia, analisa como se deu a incorporação dos ideais da Escola Nova no ensino ginasiano tradicional, em ginásios católicos, levando em conta a memória social dos seus ex-alunos, professores e contemporâneos, a convivência de dois modelos pedagógicos e, principalmente, as disputas entre católicos e escolanovistas no que diz respeito aos rumos da educação. Para tanto, estamos a analisar as memórias sociais sobre a práxis pedagógica, na região Centro-Sul da Bahia. As fontes relatos de memória, somados às fontes impressas como documentos escolares, jornais, fotografias, materiais didáticos dos ex-alunos, quando analisados à luz da dialética materialista e em diálogo com as fontes bibliográficas, nos permitirão traçar um paralelo entre a práxis educacional na região centro-sul da Bahia e as ideias pedagógicas em disputa, em correlação com os direcionamentos da educação brasileira na primeira metade do século XX.

Palavras-chave: Projeto Colúmbia; Anísio Teixeira; Educação Moderna; Educação Tradicional; Região Centro-Sul da Bahia

\begin{abstract}
The research, which is in progress, considers the implementation of the Program for Social Researches in the Bahia, and the role played for the educator Anísio Teixeira, when he was ahead of the Department of Education and Health of Bahia, and analyzes how was the embodiment of the ideals of the New School in traditional Catholics schools, considering the social memory of his former students, teachers and contemporaries, the coexistence of two pedagogical models, and, especially, the strifes between catholics and New School's supporters regarding to the direction of education. Therefore, there is an analysis about the social memories and the pedagogical praxis in the South Central region in Bahia. Some sources as reports of memory were added to the printed sources such as school records, newspapers, photographs, alumni's textbooks, everything was analyzed under the materialist dialectics and relates with literature sources, that allow us to draw a parallel between the educational praxis of central-southern Bahia and pedagogical ideas in dispute, in correlation with the directions of the Brazilian education in the first half of the twentieth century.
\end{abstract}

Keywords: Columbia Project. Anísio Teixeira. Modern Education. Tradicional Education. South-Central Region of Bahia 
A Bahia, no governo de Otávio Mangabeira (1947-1951), sofreu bastante com a crise mundial do capitalismo e com a política dos interventores do Estado Novo. Tais fatores agravaram a tendência de estagnação e a perda de posição na economia nacional que já vinha ocorrendo há muitos anos. Ao lado de outros estados nordestinos, altas taxas de mortalidade infantil, de analfabetismo, doenças, desemprego, surgimento de favelas, etc., compunham o quadro do Estado, merecendo atenção de autoridades e políticos, em debates que se prolongaram até a década de 1960 (MEDEIROS, 2009).

Alguns livros gestados na época demonstram a preocupação com a temática social, cultural, étnica e histórica. O clima intelectual era de certa tomada de consciência crítica. Clima adequado, portanto, às pesquisas e ao sentimento da necessidade de conhecer cientificamente a realidade. A Fundação idealizada por Anísio Teixeira e viabilizada por Mangabeira encontrava-se em contexto intelectualmente favorável. Conforme Ruy Medeiros,

A Fundação para o Desenvolvimento da Ciência no Estado da Bahia celebrou convênio com a Universidade de Colúmbia para pesquisas no território baiano. O Programa de Pesquisas Sociais do Estado da Bahia e o convênio celebrado em seu âmbito entre a Fundação para o Desenvolvimento da Ciência na Bahia e a Universidade de Colúmbia inserem-se no contexto do Governo Otávio Mangabeira, especialmente quanto às preocupações de parte da elite baiana com o "Enigma Baiano": cumpria conhecer a realidade da Bahia como passo importante para entender-se possibilidade de mudança (MEDEIROS, 2009, p. 96-97).

Entretanto, apesar da importância do Programa de Pesquisas Sociais do Estado da Bahia, elaborado em conjunto com a Universidade de Colúmbia (conhecido como Projeto Colúmbia University), não se pode afirmar que o mesmo tenha recomendado medidas que saneassem a pobreza e as mazelas sociais, e que da experiência de campo tenha surgido recomendações e/ou diretrizes para a educação baiana. Principalmente, se levarmos em conta que Anísio Teixeira, um dos principais articuladores do Projeto (junto com Thales de Azevedo e Luís Costa Pinto, pelo lado brasileiro), à frente da Secretaria de Educação e Saúde da Bahia em meados do século, foi um dos grandes pensadores da educação brasileira do segundo quartel do século $\mathrm{XX}$, pioneiro e um dos principais arautos da educação escolanovista.

Este artigo, que é parte de uma pesquisa mais ampla, portanto, se debruça sobre os caminhos da Educação Tradicional e a incorporação dos ideais escolanovistas, na região Centro-Sul da Bahia, mais especificamente nos colégios católicos de Vitória da Conquista, nas décadas de 40 a 60 , pretendendo entender como se dava essa discussão sobre a política educacional vigente na Bahia e no País.

A partir da década de 30, com o Manifesto dos Pioneiros da Educação Nova, iniciase oficialmente a Pedagogia da Escola Nova no Brasil. Seus postulados ganham corpo nas décadas seguintes e são implantados em detrimento da concepção pedagógica dita tradicional. Entretanto, várias categorias do modelo tradicional subsistiram, principalmente no ensino particular das escolas católicas. Por outro lado, tais estabelecimentos de ensino pago (internatos, semi-internatos e externatos) também incorporaram categorias da Escola Nova. Cabe perguntar de que modo essas duas concepções pedagógicas coexistiram na região Centro-Sul da Bahia e como os educadores regionais, formados na concepção tradicional, incorporaram esses "novos" valores educacionais nos métodos vigentes, entre 
1940 e 1960. A resposta a tal pergunta pressupõe uma investigação e análise cujo método de abordagem não pode prescindir das categorias dialéticas, a partir da contextualização histórica e geográfica do objeto em questão, bem como da teia de relações que se estabelece no âmbito econômico, social e cultural.

Vale lembrar que, no cenário do século XIX, formou-se o perfil político da região Centro-Sul da Bahia ${ }^{1}$, marcado pelo coronelismo ${ }^{2}$ o qual se estendeu por todo o período republicano. Na economia, a agricultura e a pecuária eram as atividades econômicas mais importantes, mas, desde 1920, Vitória da Conquista era conhecida pelo seu relevante comércio, que atendia à população local e à de outros municípios. Em 1940, acontecimentos locais, nacionais e internacionais afetam a economia da cidade e, dentre outras consequências, promovem sua expansão urbana. Em cadeia, vários fenômenos se determinaram simultaneamente: Segunda Guerra Mundial, impulsionando a exportação; o surgimento da Rio-Bahia, possibilitando a expansão ao Sul e Sudeste, a integração à Região Cacaueira e à Capital; ocupação de novos espaços da cidade, a partir do centro; impulsos de modernização. Mas, neste interregno, a população rural era três vezes maior que a urbana (MEDEIROS, 2002).

Segundo a memória e as representações de alguns dos sujeitos que vivenciaram muitas experiências no campo educacional da região, nas décadas de 1940 a 1960:

Vitória da Conquista era, pela sua localização geográfica, um pólo dentro do setor comercial, e trazia muito progresso em termos comerciais e de propriedades rurais destinadas à pecuária, e abarcava uma região promissora, a exemplo de Itambé, Itapetinga, Poções, e não tinha um curso de ginásio nessa microrregião. Então Conquista atendia a essa microrregião. [...] próximo a Conquista nós tínhamos em Caetité, tínhamos em Jequié, tínhamos em Jaguaquara e só. ${ }^{3}$

A primeira escola a oferecer o curso ginasial em Vitória da Conquista foi fundada e dirigida em 1940, pelo padre diocesano Luiz Soares Palmeira ${ }^{4}$. Nesta instituição de ensino particular, única alternativa de curso ginasial num espaço regional que compreendia muitos povoados e municípios, as concepções de educação, os procedimentos didáticos, as temáticas e conteúdos trabalhados estavam em consonância com as propostas oficiais vigentes na época. Tratava-se de um ensino marcado pelo dualismo educacional em relação às classes e aos gêneros; um ensino elitista, cívico e enciclopédico; um estilo acadêmico inspirado no ensino secundário brasileiro dos 40 e 50, que, segundo Jayme Abreu (2005, p.41), era dominado por um "humanismo beletrista de inspiração clássica".

$\mathrm{Na}$ década de 50, Vitória da Conquista vive um significativo crescimento populacional, sobretudo urbano, acompanhado do surgimento do mercado imobiliário e de modificações no quadro socioeconômico, sinalizadas pela ampliação do comércio, favorecido com a abertura das estradas Ilhéus-Lapa e Rio-Bahia (MEDEIROS, 2002).

Em 1956, o Ginásio Nossa Senhora de Fátima, conhecido como Sacramentinas, foi fundado em Vitória da Conquista - BA. Mantido pela Congregação das Religiosas do Santíssimo Sacramento ${ }^{5}$, sua política educacional inspirou-se na formação do homem, baseada nos valores morais, intelectuais e religiosos, comprometida com o ideal educativo e missionário legado pelo fundador Pe. Pierre Vigne ${ }^{6}$, chamado de "o grande Missionário Educador". Esta instituição cuidaria da educação das crianças e dos jovens, tendo por tarefa primordial "fazer com que os homens conheçam, amem e glorifiquem a Jesus" e, 
ainda, promover "o crescimento humanístico das crianças e da juventude desta cidade e regiões adjacentes". 7

No período focado, a iniciativa de fundar e dirigir escolas, sobretudo secundaristas, pode ser apontada em muitos centros urbanos do país, pois ela reflete as demandas do contexto socioeconômico da época e reflete também as históricas disputas entre as propostas pedagógicas religiosas e as propostas pedagógicas laicizantes ${ }^{8}$ (influenciadas pelo pensamento iluminista), que se dão a partir do século XVIII - período em que os contrastes entre a fé e a lógica, entre a religião e a ciência resultam em decisivas alterações na educação escolar, especialmente no Brasil.

A memória social evidencia a trajetória dessas e de outras instituições de ensino que movimentaram o cenário escolar, político e cultural do Centro-Sul da Bahia, especialmente Vitória da Conquista, com diretores, professores e alunos que protagonizaram ou contribuíram significativamente para importantes mudanças na realidade de alguns municípios da região, se destacando, ademais, como políticos, jornalistas, escritores, poetas, artistas, religiosos e intelectuais. Essas instituições estão imortalizadas na memória regional por seu pioneirismo elou por uma anunciada contribuição intelectual, cultural e política para o desenvolvimento regional. ${ }^{9}$ Os relatos dos ex-alunos, geralmente referem-se a um espaço onde "homens inteligentes, rígidos, polivalentes" sempre "falavam da vida com sabedoria e profundidade." 10

Além dos estudantes do município, o Ginásio e as Sacramentinas receberam adolescentes e jovens, oriundos das famílias abastardas, de toda a região Sudoeste da Bahia e Norte de Minas, reafirmando para Vitória da Conquista uma posição de polo econômico e cultural. Por essa razão, estabelecemos esse município como o recorte espacial dessa pesquisa.

O caráter clássico das aulas ministradas no Ginásio e nas Sacramentinas estava expresso não apenas nos conteúdos, mas, também, nos métodos e na orientação moral, o que ilustra o perfil de uma escola tradicional, conservadora, cujo modelo de educação foi disseminado pelos Jesuítas ${ }^{11}$ e ratifica o propósito central da educação, de formar jovens disciplinados e ordeiros; defensores dos valores e projetos políticos estabelecidos; fiéis ao ideal de sociedade, compatível com a fé cristã e com toda a infraestrutura e superestrutura necessárias à permanência do modo capitalista de produção.

Mormente, essas instituições, ainda que particulares e de vocação católica, refletiam o ideal de educação hegemônico no país, legalizado e imposto pelas leis orgânicas do ensino, cujo caráter pedagógico-didático vigorou entre 1940 e 1960. Nesse período, as correntes filosóficas que tratam dos fundamentos da educação brasileira foram divididas, principalmente, nas concepções: humanista tradicional (representada pela ideologia católica) e humanista moderna (representada pela ideologia escolanovista) (SAVIANI, 1998).

Dentre os dois vieses que compunham o humanismo tradicional, o religioso (de bases medievais) e o leigo (de bases no pensamento moderno), concordamos com o referido autor de que o segundo viés inspirou a construção do 'sistema público de ensino', laico, obrigatório e gratuito, num momento em que a burguesia se consolidava. $\mathrm{O}$ humanismo moderno (que inspirou a Escola Nova) se evidencia na política educacional brasileira a partir de 1930, predominando a partir de 1945 (após o Estado Novo) e no inicio da reabertura democrática (SAVIANI, 1998).

Contudo, conforme Severino (2002), as concepções de educação que se inspiraram inicialmente na visão teológico-cristã e, em seguida, nas perspectivas cientificistas, não promoveram a superação total do humanismo tradicional pelo humanismo moderno. No caso aqui estudado, as informações dos sujeitos históricos que estiveram no campo 
educacional da região estudada, no referente à metodologia aplicada nas escolas católicas, sugerem a coexistência dos princípios filosóficos do humanismo tradicional e do humanismo moderno ${ }^{12}$.

Desta forma, como organismos não isolados, o Ginásio de Conquista e o Ginásio das Sacramentinas espelhavam as tendências educacionais da época, que, por sua vez, eram reflexos da composição social e ideológica, das inovações culturais, dos avanços técnicos e científicos, que compunham as condições históricas determinadas pelas transações políticas e econômicas da primeira metade do século XX. Mantinham, porém, suas especificidades regionais.

Essas são as razões que justificam e delineiam o estudo da práxis educacional na região Centro-Sul baiana, ou seja, as trajetórias, os estranhamentos, as superações e a coexistência das concepções pedagógicas Tradicional e Escolanovista no pensamento e nas ações desenvolvidas nas instituições de ensino de Vitória da Conquista, tendo como foco as histórias e as memórias do Ginásio de Conquista e do Ginásio das Sacramentinas.

Para levar avante esta proposta, recorremos teoricamente a Saviani (1996) que, ao pensar na educação enquanto objeto científico e filosófico, explica que o ponto de partida da filosofia são os problemas enfrentados no cotidiano, algo que perturbe os indivíduos no transcurso da sua existência e que, portanto, deve ser pesquisado para ser resolvido. Nesse ínterim, reiteramos que a questão que justifica este projeto de pesquisa aponta para uma lacuna na história de Educação regional posto que interroga como se deu a transição elou a coexistência entre os ideais da Educação Tradicional e da Educação Escolanovista, nos métodos, técnicas, fundamentos pedagógicos e direcionamento moral e religioso das escolas da região Centro-Sul da Bahia, problema até então não estudado.

Estas, portanto, são as considerações que nos permitem esboçar uma análise da prática e do pensamento pedagógico vigente no Centro-Sul baiano, durante a primeira metade do século $\mathrm{XX}$, destacando as transformações e permanências das referidas concepções, a partir da memória social, posicionando o fenômeno no tempo/espaço específico da sua trajetória, apreciando as crises e os avanços da educação brasileira, de modo a propiciar um estudo histórico do pensamento educacional regional, mediante uma abordagem da relação entre Memória, Cultura e Educação e, ao mesmo tempo, contribuir com as pesquisas no campo da Memória e da relação Estado, Igreja e Educação no Brasil no contexto republicano.

A história da educação no Brasil, de modo geral, aponta os interesses, as preocupações e as ações da Igreja Católica, no campo da educação escolar (SAVIANI, 2008; SCHWARTZMAN, 2000) e, na primeira metade do século XX, parece notável o seu empenho para a fundação e direção de instituições de ensino, inclusive em Vitória da Conquista.

No Brasil, desde os mais antigos colégios no século XIX - os Liceus Provinciais as iniciativas de abrir escolas significou, na prática, a educação para poucos, e essa concepção caracterizará a educação na República, até 1961, quando é promulgada a primeira Lei de Diretrizes e Base da Educação (LDB) ${ }^{13}$ (NUNES, 2000).

Contudo, as diferentes e variadas visões sobre o espírito da educação começam a preocupar os governantes brasileiros a partir de 1930, quando as ideologias têm presença mais forte na vida política e a Educação se torna uma das principais arenas de combate ideológico. Nesse momento, as diferentes opiniões começam a se cristalizar e polarizamse, prevalentemente, em: Movimento da Escola Nova e Proposta da Igreja Católica.

Em 1940, as ideias gestadas desde décadas anteriores foram sistematizadas com mais qualidade e entraram em confronto. O Movimento da Escola Nova (com ideias liberais), ao lado da Renovação Católica (conservadora e moralista) e da Proposta Fascista 
(com ideias autoritárias), teve amplo destaque. ${ }^{14}$ Embora não constituísse projeto definido e congregasse pensamentos liberais não homogêneos, o Movimento Escolanovista defendia grandes temas como: escola pública, universal e gratuita; igualdade básica de oportunidade em que floresceriam as diferenças baseadas nas qualidades pessoais; setor público (ensino leigo) com função de formar o cidadão livre e consciente para incorporá-lo ao grande Estado Nacional; princípios pedagógicos afastados do autoritarismo, com processos mais criativos e menos rígidos; conteúdos relacionados à vida comunitária, que seria pública, mas não burocrática.

Nos anos de 1932 a 1969, segundo Saviani (2008), houve a predominância da chamada Pedagogia Nova. O autor dividiu esse período em três: no primeiro (1932-1947) temos a coexistência da pedagogia tradicional (que poderia ser classificada por uma vertente religiosa e uma vertente leiga) e da pedagogia nova. Com base em pressupostos liberais e pragmáticos, a pedagogia nova, representada principalmente por Anísio Teixeira, Lourenço Filho e Fernando de Azevedo, tinha por bandeira o "aprender a aprender" e o "aprender a fazer". Centralizando a prática pedagógica no aluno, opunha-se ao método pedagógico tradicional. Mas, os interesses políticos que estavam em jogo não permitiram que essa coexistência da pedagogia tradicional e da pedagogia nova fosse tranquila. No caso, as reformas educacionais de Vargas, entre 1930 e 1940, tentavam atender aos diversos interesses desses grupos que buscavam o reconhecimento político de sua concepção pedagógica.

No segundo período (1947-1961), as reformas educacionais priorizaram as propostas escolanovistas, que, entretanto, não contemplavam as necessidades educacionais da maioria da população brasileira, ainda desescolarizada e analfabeta. Segundo o autor, o predomínio dessas ideias escolanovistas se dá num contexto de crescimento econômico e liberal do país, desde 1964 (SAVIANI, 2008).

No terceiro período (1961-1969), a pedagogia nova vive uma crise graças à germinação da pedagogia tecnicista, preocupada em formar mão-de-obra para o mercado de trabalho, que se expandia na indústria urbana. A formação de pessoas eficientes para o trabalho, que não precisavam ser críticas ou criativas, era interesse político do regime militar instaurado no país.

Todo o panorama histórico apresentado por Saviani sinaliza o empenho da instituição religiosa em tornar-se, também, instituição educativa. Embora não tenhamos elementos e fontes suficientes para afirmar que o Ginásio de Conquista e o Ginásio das Sacramentinas, nos anos 40 a 60, em Vitória da Conquista, pertenceram a essa disputa entre Escola Nova e Igreja Católica, podemos investigar as interferências de tal debate nessas instituições que, embora fossem particulares e dirigidas por religiosos católicos, aderiram, em parte, a uma política pedagógica orientada pelos ideais laicizantes difundidos pela Escola Nova, sem, contudo, ter eliminado todos os elementos tradicionais da educação, como sugerem algumas fontes orais já consultadas.

O processo de investigação requereu que, antecipadamente, fossem traçados caminhos que aproximassem e distanciassem pesquisador e objeto, numa justa medida. No caso específico desse projeto, que traz a proposta de investigar a coexistência da Educação Tradicional e da Educação Moderna na região Centro-Sul da Bahia, nas décadas 1940 a 1960, os passos seguidos conduzem a pesquisa para o ambiente circunscrito à região estudada, a fim de interpretarmos os seus elementos e as questões relacionadas ao recorte específico, ao local. Nesse tempo, conduzimos a pesquisa para o "mundo" onde o fenômeno foi gerado, a fim de identificar e compreender suas relações, internas e externas, ou seja, os movimentos da modernidade e o direcionamento da educação para atender a novas demandas econômicas e sociais, no todo e nas partes. 
Neste movimento global do conhecimento, partimos da fragmentação empírica (objeto como se apresenta à observação imediata) e, por meio da análise, pretendemos chegar às múltiplas determinações do fenômeno para, finalmente, através de uma síntese, chegarmos novamente ao objeto, agora entendido não mais como "representação caótica de um todo", e sim, como uma totalidade de determinações e de muitas relações (MARX, 1973; 1982). Ou seja, tratamos da trajetória de duas instituiçõos escolares católicas e de seus sujeitos compreendendo que ambos estão definidos pela materialidade que os cerca ou na qual eles estão inseridos.

Para tanto, recorremos à memória social das gerações contemporâneas ao fenômeno estudado, ao tempo em que levamos em consideração as condições históricas da primeira metade do século XX; os pensamentos e as políticas educacionais em disputa e em evidência, no plano da totalidade; e, principalmente, os fundamentos que embasaram o pensar e o fazer pedagógico no Brasil.

Ao pensarmos no contexto da inserção do Ginásio de Conquista e do Ginásio das Sacramentinas, nas suas primeiras décadas de funcionamento, consideramos as múltiplas determinações que lhes impunham uma caracterização e que influenciaram a história dessas Instituições. Embora com a atenção voltada para as questões relativas à educação e à política educacional oficial, necessariamente, discutimos as dimensões econômicas, políticas e socioculturais que marcaram a sociedade da época. Afinal, compreendemos que a educação não se processa isoladamente; ao contrário, ela é resultante e resultado do modo como a sociedade está organizada na produção da sua vida material e da sua vida social.

As duas instituições de ensino que são pesquisadas não "surgiram" no sertão da Bahia como fruto de uma ação inintencional. Elas foram pensadas e atenderam a interesses prévios, que podem ser compreendidos se pensarmos no cenário local e nacional e na educação brasileira da primeira metade do século XX. Portanto, merece enfoque o contexto histórico educacional, sobretudo no Brasil, e seus reflexos no município de Vitória da Conquista, entre as décadas de 1940 e 1960, período no qual foram fundados os dois.

Como já foi dito, esta pesquisa se debruça sobre os caminhos da Educação Tradicional e a incorporação dos ideais escolanovistas, na região Centro-Sul da Bahia, mais especificamente nos colégios católicos de Vitória da Conquista, nas décadas de 40 a 60 , pretendendo entender como se dava essa discussão sobre a política educacional vigente na Bahia e no País. Carece, então tentar evidenciar vínculos entre as ações políticas do governo estadual no que diz respeito ao desenvolvimento social e a educação oficial, pública e privada.

Cabe perguntar de que modo essas duas concepções pedagógicas coexistiram na região Centro-Sul da Bahia, como as autoridades oficiais se posicionaram, pensaram e dirigiram a educação oficial neste período e como os educadores regionais, formados na concepção tradicional, incorporaram esses "novos" valores educacionais nos métodos vigentes, entre 1940 e 1960. E reafirmamos, principalmente, a necessidade de levar em conta que Anísio Teixeira, um dos principais articuladores do Projeto, Secretário de Educação e Saúde da Bahia em meados do século, era, portanto, responsável pela educação na capital e no interior do Estado.

\section{Referências}

ABREU, Jayme. A Educação Secundária no Brasil: Ensaio de identificação de suas características principais. (Trabalho apresentado ao Seminário Interamericano de 
Educação Secundária. Santiago do Chile. 1955. Publicado originalmente na RBEP v. 23, n. 58, p. 26-104, abr./ jun. 1955). 2005.

AGUIAR, Edinalva Padre et alli. Política: O Poder em Disputa. Vitória da Conquista e Região: Museu Regional de Vitória da Conquista/Universidade Estadual do Sudoeste da Bahia, 1999 (Série Memória Conquistense).

BUAINAIN, Maria Jeanne D'Arc. Atividades Educacionais da Congregação Sacramentina. São Carlos: Irmãs Sacramentinas. 1991.

CUNHA, Luiz Antônio. A universidade temporã. 2. ed. Rio de janeiro: Francisco Alves, 1986.

EISENBERG, José. As Missões Jesuíticas e o Pensamento Político Moderno: encontros culturais, aventuras teóricas. 1. ed. Belo Horizonte: Editora UFMG, 2000.

IRMÃS SACRAMENTINAS. Padre Vigne, Missionário e Educador. São Carlos: Edições Loyola, p.21-23, 1990.

LEAL, Victor Nunes. Coronelismo, Enxada e Voto: O município e o regime representativo no Brasil. 3. ed. Rio de Janeiro: Nova Fronteira, 1997.

MARX, Karl. Contribuição para a crítica da economia política. 2. ed. Lisboa: Estampa, 1973.

Para a crítica da economia política; Salário, preço e lucro; $O$ rendimento e suas fontes: a economia vulgar. São Paulo: Abril Cultural, 1982.

MEDEIROS, Ruy Hermann de Araújo. (coord.) Projeto: Documentação e Registro Audiovisual da Arquitetura e Evolução Urbana de Vitória da Conquista. Vitória da Conquista. 2002.

MEDEIROS, Ruy Hermann de Araújo. O Programa de Pesquisas Sociais do Estado da Bahia - Universidade de Colúmbia. Quaestio: Revista de Estudos em Educação. Volume 11, n. 1, 2009.

NUNES, Clarice. O "velho" e "bom" ensino secundário: Momentos Decisivos. In. Revista Brasileira de Educação. Associação Nacional de Pós-Graduação e Pesquisa em Educação. São Paulo: Autores Associados, 2000. n. 014. mai-ago, p. 35-60.

OLIVEIRA, Edileusa Santos. O Ginásio de Conquista - a memória de uma instituição escolar (1940-1960). Vitória da Conquista - BA: UESB, 2009 (Dissertação de Mestrado).

SAVIANI, Dermeval. Educação: do senso comum à consciência filosófica. 12. ed. Campinas, São Paulo: Autores Associados, 1996.

História das idéias pedagógicas no Brasil. Campinas, SP: Autores Associados, $2^{\text {a }}$ ed., 2008. (Coleção Memória da Educação). 
SCHWARTZMAN, Simon. Tempos de Capanema. São Paulo: Paz e Terra: Fundação Getúlio Vargas, 2000.

SERPA, Luiz Felippe Perret. Anísio Teixeira: O Missionário Moderno. In. Revista Especiarias. UESC. Ano III, nº 5, Ilhéus: Editus, 2001.

SEVERINO, Antonio Joaquim. A filosofia da educação no Brasil: esboço de uma trajetória. In: GHIRALDELLI JR., Paulo. (org.). O que é filosofia da educação? 3. ed. Rio de Janeiro: DP\&A, 2002.

SOUZA. Daniela Moura Rocha de. Memória de Professores Intelectuais como Interlocutores do Republicanismo em Vitória da Conquista entre os anos de 1910 até 1945. Vitória da Conquista - BA: UESB, 2009. (Dissertação de Mestrado).

\section{FONTES:}

Site:

Colégio Sacramentinas.

Disponível em: <http://www.colegiosacramentinas.com.br/?page_id=2ไhistórico>. Acesso em: 09 de fevereiro. 2012.

Notas

1 No Centro-Sul da Bahia, os graves conflitos entre famílias tradicionais locais foram legitimados pela estrutura política e administrativa do Império, que acarretava, nas localidades, o uso de violência por grupos políticos divergentes que desejavam controlar o poder administrativo municipal (AGUIAR, 1999).

2 Segundo Victor Nunes Leal (1997), o coronelismo foi uma forma peculiar de manifestação do poder privado, coexistindo com um regime político de extensa base representativa. Ele apresenta a figura do "autêntico coronel", representada pelo grande proprietário pouco ilustrado, em contraste com a figura dos "ilustrados doutores", representada pelos profissionais liberais.

3 Uady Barbosa Bulos, ex-aluno do Ginásio de Conquista de 1952 a 1955, "pessoa de notório saber". Advogado. Entrevista concedida em 29 de maio de 2008, aos 68 anos.

4 Luiz Soares Palmeira nasceu no Rio de Janeiro - RJ, em 25 de junho de 1906, e faleceu em Salvador BA, em 29 de dezembro de 1988. Filho de uma família abastada, que combinava religião, educação e uma grande participação política, Palmeira mudou-se para Caetité, município do interior baiano, onde recebeu as "ordens" eclesiásticas, em 1932, e fundou um Ginásio que em 1939 foi transferido para Vitória da Conquista.

5 A Congregação das Religiosas do Santíssimo Sacramento foi fundada por Pierre Vigne, um sacerdote católico, em 1715, em Boucieu-Leroy, e tem sua sede no Parque de São Vítor, em Valença - França. Em 1903, foram enviadas para o Brasil 5 irmãs que, instalando-se em Salvador, iniciaram um trabalho de caráter missionário e educativo. Mas, somente em 1956 as irmãs se instalaram em Vitória da Conquista, dando surgimento à nova comunidade e ao Ginásio Nossa Senhora de Fátima (BUAINAIN, 1991).

6 Pierre Vigne nasceu em Privas-França, 20 de agosto de 1670, e faleceu em Rencurel, em 1740. Criado no seio de uma família calvinista, converteu-se ao cristianismo e tornou-se sacerdote em 1694. Depois de concluir os estudos de Teologia no Seminário de São Sulpício, submetendo-se aos exames para iniciar os estudos superiores, na Universidade de Valença, Pe. Vigne recebeu o título de "Mestre" ao demonstrar profundo conhecimento teológico-pedagógico e, desde então, dedicou-se a amplas atividades pedagógicas. Dono de uma biblioteca com aproximadamente 500 livros, onde mesclavam-se obras de teologia, filosofia, letras e ciências, e "vivendo nos tempos modernos, Pe. Vigne deixou-se influenciar pelos renascentistas", além de aceitar e divulgar as normas didáticas do século XVII escritas por Comênio, ao tempo em que, como Missionário, "fez da religião princípio, meio e fim da educação". (IRMÃS SACRAMENTINAS. Padre Vigne, Missionário e Educador. São Carlos: Edições Loyola, p.21-23, 1990). 
7http://www.colegiosacramentinas.com.br/?page_id=2〈histórico

8 O dualismo: 'religiosidade e pragmatismo' é característico na obra de Anísio Teixeira, um dos grandes expoentes da Escola Nova no Brasil que, aderindo ao pensamento de Dewey, teria conservado algumas prerrogativas da sua educação jesuítica (SERPA, Luiz Felippe Perret. Anísio Teixeira: O Missionário Moderno. In. Revista Especiarias. UESC. Ano III, nº 5, Ilhéus: Editus, 2001).

9 Sobre a memória de professores que ganharam evidência pública por terem atuado no papel de intelectuais em Vitória da Conquista, durante a Primeira e Segunda República, ver a Dissertação de Mestrado intitulada: "Memória de Professores Intelectuais como Interlocutores do Republicanismo em Vitória da Conquista entre os anos de 1910 até 1945”, de Daniela Moura Rocha de Souza, sob orientação da Profa. Dra. Lívia Diana Rocha Magalhães, apresentada ao Programa de Pós-Graduação em Memória: Linguagem e Sociedade, em 2009.

10 As expressões que estão entre aspas dizem respeito aos relatos orais de ex-alunos do Ginásio de Conquista, entrevistados entre 2005 e 2009, publicados na Dissertação intitulada: "O Ginásio de Conquista a memória de uma instituição escolar (1940-1960)”, de Edileusa Santos Oliveira, sob orientação da Profa. Dra. Ana Elizabeth Santos Alves, apresentada ao Programa de Pós-Graduação em Memória: Linguagem e Sociedade, da Universidade Estadual do Sudoeste da Bahia (UESB), em 2009.

11 Sobre a influência e permanência das categorias do ensino jesuítico na educação brasileira moderna, ler "As Missões Jesuíticas e o Pensamento Político Moderno: encontros culturais, aventuras teóricas" (EISENBERG, 2000). Para o autor, "as missões jesuíticas do Novo Mundo formam o contexto histórico e intelectual do desenvolvimento do pensamento político-jesuítico do início da era moderna", na medida em que "uma primeira geração de missionários no Brasil buscava definir novas estratégias de justificação que lhes permitissem adaptar e alterar a doutrina religiosa na qual haviam sido educados para os fins práticos de seu empreendimento no Novo Mundo", dessa forma, os escritos dos missionários jesuítas em atividade na América portuguesa antecipam os paradigmas fundamentais do pensamento político europeu dos séculos XVI e XVII (p. 14).

12As informações supramencionadas foram retiradas das entrevistas feitas, entre 2005 e 2012, com ex-alunos e ex-professores do Ginásio de Conquista e do Ginásio das Sacramentinas, que conviveram nas instituições entre 1940 e 1960. Segundo uma ex-aluna das Sacramentinas, na metodologia vigente na década de 50 "podia-se vê claramente o cruzamento entre métodos jesuíticos e escolanovistas, no canto, nas preleções morais, nos trabalhos em equipe etc.

13 Anísio Teixeira considerou que a LDB, promulgada em 20 de dezembro de 1961, ficou aquém das necessidades do Brasil; mas significou um avanço da orientação liberal e descentralizadora, inspirada na proposta pedagógica dos renovadores dos anos 20 . O ponto negativo foi a abertura dada à iniciativa privada, contradizendo o ideal escolanovista de reconstruir a educação através de um forte sistema público de ensino. Contudo, foi considerada uma conquista o "tratamento igualitário conferido aos diversos ramos do ensino médio, abolindo a discriminação contra o ensino profissional que marcou as leis orgânicas do ensino herdadas do Estado Novo" (SAVIANI, 2008, p.307), segundo as quais o acesso ao nível superior se dava apenas através do ensino secundário, ficando os concluintes de outras modalidades de ensino médio (cursos comercial, industrial e agrícola; curso normal; curso de formação de oficiais militares) impedidos de se candidatarem ao ensino superior. Segundo o autor, agora, o ensino profissional estaria equiparado ao ensino médio (SAVIANI, 2008).

14 A ideologia da Ação Integralista Brasileira (AIB) - movimento fascista brasileiro, criado em 1932, sob a liderança de Plínio Salgado - defendia os valores "cristãos", ensinados para facilitar a aceitação da ordem estabelecida e do "destino"; os valores rústicos, que permitiam às oligarquias a exploração de trabalhadores e pequenos proprietários; os interesses da "pátria", ou seja, do Estado, sobre os interesses particulares das classes sociais, principalmente os que ameaçavam a ordem. Contudo, ao mesmo tempo em que a ideologia e as práticas políticas fascistas ganhavam simpatizantes nas camadas médias, alguns setores destas tornavam-se contrários ao integralismo, defendendo propostas democráticas, socialistas ou liberais (CUNHA, 1986).

Recebido em out/2013

Aprovado em out/2013 